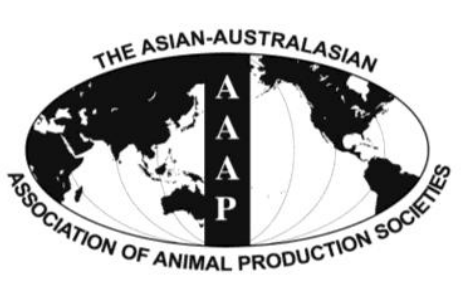

Open Access

Asian Australas. J. Anim. Sci.

Vol. 27, No. 6 : 791-796 June 2014

http://dx.doi.org/10.5713/ajas.2013.13565

www.ajas.info

pISSN 1011-2367 elSSN 1976-5517

\title{
L-carnitine Supplemented Extender Improves Cryopreserved-thawed Cat Epididymal Sperm Motility
}

\author{
S. Manee-in*, S. Parmornsupornvichit ${ }^{1}$, S. Kraiprayoon ${ }^{1}$, T. Tharasanit ${ }^{2}$, P. Chanapiwat, and K. Kaeoket \\ Department of Clinical Sciences and Public Health Medicine, Faculty of Veterinary Science, Mahidol University, \\ Nakhon Prathom 73170, Thailand
}

\begin{abstract}
Cryopreservation of epididymal sperm is an effective technique to preserve genetic materials of domestic cats and wild felids when they unexpectedly die. However, this technique inevitably causes detrimental changes of cryopreserved-thawed spermatozoa, for example, by physical damage and excessive oxidative stress. L-carnitine is an antioxidant that has been used to improve sperm motility in humans and domestic animals. This study aimed to investigate the effects of L-carnitine on cat epididymal sperm quality following cryopreservation and thawing. After routine castration, cauda epididymides were collected from 60 cat testes. The epididymal spermatozoa from 3 cauda epididymides were pooled as 1 replicate. Spermatozoa samples (16 replicates) were examined for spermatozoa quality and then randomly divided into 4 groups: $0 \mathrm{mM} \mathrm{L}$-carnitine (control), $12.5 \mathrm{mM}, 25 \mathrm{mM}$ and $50 \mathrm{mM}$ L-carnitine. The sperm aliquots were then equilibrated and conventionally frozen. After thawing, sperm motility, plasma membrane integrity, DNA integrity and acrosome integrity were evaluated. The $25 \mathrm{mM}$ L-carnitine significantly improved sperm motility compared with a control group $(\mathrm{p}<0.05)$, although this was not significantly different among other concentrations. In conclusion, supplementation of $25 \mathrm{mM}$ L-carnitine in freezing extender improves cauda epididymal spermatozoa motility. The effects of L-carnitine on the levels of oxidative stress during freezing and thawing remains to be examined. (Key Words: L-carnitine, Epididymal Spermatozoa, Cryopreservation, Cat)
\end{abstract}

\section{INTRODUCTION}

In recent years, cryopreservation is an attractive subject with the purpose of establishing an efficiently gene bank model to be used for threatened and endangered male breeders. This technique has a potential mean of enabling long-term storage and transport of viable genetic materials (Pena et al., 2003; Thuwanut et al., 2010). Cryopreservation has many benefits for long-term preservation, artificial insemination, breeder's death and over distance of breeder (Bailey et al., 2000). Although ejaculated spermatozoa have

\footnotetext{
* Corresponding Author: S. Manee-in. Tel: +66-2-4415242, Fax: +66-2-4410937, E-mail: sukanya.man@mahidol.ac.th

${ }^{1}$ Faculty of Veterinary Science, Mahidol University, Nakhon Prathom 73170, Thailland.

${ }^{2}$ Faculty of Veterinary Science, Chulalongkorn University, Bangkok 10330, Thailand.

Submitted Sept. 12, 2013; Revised Dec. 30, 2013; Accepted Feb. 1, 2014
}

been successfully cryopreserved, this technique has met a limited success when applied to epididymal spermatozoa, probably because of the differences in morphology, function and also the membrane stability between the epididymal and ejaculated spermatozoa (Thuwanut and Chatdarong, 2009). Cryopreservation of epididymal spermatozoa is a technique of choice to preserve genetic potential of provenfertility toms when they unexpectedly die or fail to obtain ejaculated spermatozoa. It is therefore important to improve freezing technique for feline spermatozoa recovered from caudal epididymis.

Previous studies demonstrated that freezing and thawing potentially induce cryoinjuries (Pena et al., 2005; Thomson et al., 2009; Zini et al., 2009; Kim et al., 2010b), all of which are critical for sperm morphology, acrosome integrity and survival rate (Cerolini et al., 2001). During cooling and freezing processes, cold shock frequently occurs if temperature is reduced too rapidly. This causes extensive 
intracellular ice formation and is detrimental to sperm plasma membrane (Hammerstedt et al., 1990). Suboptimal cooling and freezing rates would therefore increase the production of free radicals, oxidants and reactive oxygen species (ROS) resulting in decreasing of membrane fluidity, increase DNA fragmentation and decrease the fertilizability of spermatozoa (Bailey et al., 2000; Thomson et al., 2009; Kim et al., 2010a; Aitken and Koppers, 2011).

The antioxidant supplementation in freezing extender has been used to defend against free radicals that potentially reduce sperm fertilizing ability. L-carnitine is an antioxidant that plays a role in spermatozoa motility (Stradaioli et al., 2004; Abd-Allah et al., 2009), enhances cellular energy in mitochondria, protects sperm membrane and DNA from ROS induced apoptosis (Agarwal et al., 2004). L-carnitine and free L-carnitine are naturally present in epididymal seminal plasma to support spermatozoa motility and maturation. L-carnitine has been reported to uptake by boar epididymal spermatozoa by passive and active diffusion depending on regions and expose duration of substances (Jeulin et al., 1994; Kobayashi et al., 2007). L-carnitine supplementation could improve spermatozoa motility in stallions whose had spermatozoa motility less than $50 \%$ (Stradaioli et al., 2004). Oral administration of L-carnitine in human with idiopathic asthenozoospermia also demonstrated the improvement of spermatozoa quality (Costa et al., 1994). Until the present, the cryoprotective effect of L-carnitine during freezing and thawing remains unclear. Therefore, this study was performed to investigate the effects of different L-carnitine concentrations in the freezing extender on post-thaw quality of feline epididymal spermatozoa.

\section{MATERIALS AND METHODS}

The animal intervention was approved by the Faculty of Veterinary Science-Animal Care and Use Committee (FVSACUC), Mahidol University.

\section{Experimental design}

Feline spermatozoa were collected from cauda epididymides. Spermatozoa morphology, motility, plasma membrane integrity, acrosome integrity and DNA integrity were evaluated immediately after spermatozoa extraction. After spermatozoa samples were centrifuged and the supernatant was removed, the sperm pellets were diluted with Tris-glucose based extenders supplemented with different concentrations of L-carnitine: i) $0 \mathrm{mM} \mathrm{L}$-carnitine (control), ii) $12.5 \mathrm{mM} \mathrm{L}$-carnitine, iii) $25 \mathrm{mM} \mathrm{L}$-carnitine and iv) $50 \mathrm{mM} \mathrm{L}$-carnitine. The spermatozoa were then conventionally cryopreserved. Spermatozoa motility, plasma membrane integrity, acrosome integrity and DNA integrity were evaluated at 0,2 and 4 hours after thawing.

\section{Preparation of freezing medium}

Freezing extender used in this study was Tris-glucose based extender containing 2.4\% (w/v) Tris (BDH, England), $1.4 \%(\mathrm{w} / \mathrm{v})$ citric acid (BDH, England), $0.8 \%(\mathrm{w} / \mathrm{v})$ glucose (Merck, Germany), 0.06\% (w/v) sodium benzyl penicillin (M\&H manufacturing co., Ltd., Samutprakarn, Thailand), $0.1 \%(\mathrm{w} / \mathrm{v})$ streptomycin sulphate (M\&H manufacturing co., Ltd., Samutprakarn, Thailand), and different concentrations of L-carnitine (Sigma-Aldrich, St. Louis, MO, USA) (0 mM L-carnitine, $12.5 \mathrm{mM}, 25 \mathrm{mM}$, and $50 \mathrm{mM}$ ). This extender was further supplemented with 3\% and 7\% (v/v) glycerol for extender 1 and 2, respectively. Thawing medium used in this study was prepared similarly to freezing extender except that it did not contain egg yolk, L-carnitine or glycerol (Axner et al., 2004).

\section{Animals and collection of epididymal spermatozoa}

Testes were collected from 24 healthy cats of various breeds, aged between 1-7 years old by routine closedtechnique castration. They were immediately kept in $0.9 \%$ (w/v) normal saline solution supplemented with penicillinstreptomycin at room temperature until epididymal spermatozoa extraction. The epididymal spermatozoa from 3 cauda epididymides were randomly pooled as 1 replicate in order to increase the sperm numbers and also to reduce individual variations. A total of 16 replicates were performed in this study. To obtain the spermatozoa, cauda epididymides were cut into few pieces and then placed in thawing medium for $10 \mathrm{~min}$ at $37^{\circ} \mathrm{C}$ (Tittarelli et al., 2006). The sperm samples that contained with more than $70 \%$ motility and normal morphology were only used in this experiment.

\section{Spermatozoa cryopreservation and thawing}

The sperm suspension was centrifuged at $700 \times \mathrm{g}$ for 6 min, and the sperm pellet was resuspended in extender 1 . After equilibration at $4^{\circ} \mathrm{C}$ for $1 \mathrm{~h}$, an equal volume of extender 2 was slowly added (Axner et al., 2004). The spermatozoa were loaded into a $0.25 \mathrm{~mL}$-straw and then frozen by placing the straw horizontally $4 \mathrm{~cm}$ above liquid nitrogen vapors for $10 \mathrm{~min}$. The straw was finally immersed in the liquid nitrogen (Andersen, 1975).. Thawing procedure was performed by immersing the straw in warm water $\left(37^{\circ} \mathrm{C}\right)$ for $15 \mathrm{~s}$. The frozen-thawed semen was then released into a pre-warmed thawing medium $\left(37^{\circ} \mathrm{C}\right)$. After incubation at $37^{\circ} \mathrm{C}$ for $5 \mathrm{~min}(0 \mathrm{~h})$ and at 2 and 4 hours in thawing medium, the sperm suspensions were evaluated for sperm motility, plasma membrane integrity, acrosome integrity and DNA integrity.

\section{Sperm morphology and motility evaluation}

A five $\mu \mathrm{L}$ of sperm suspension was put on a pre-warmed slide and then covered with a coverslip at $37^{\circ} \mathrm{C}$. Sperm 
motility and progressive motility were blindly evaluated by the same person under a phase-contrast microscope at $200 \times$ for 8-10 fields following the criteria of Platz and Seager (1978). Regarding tail morphology, fresh sperm suspension ( $2 \mu \mathrm{L}$ ) was diluted with $100 \mu \mathrm{L}$ of formal saline, and a total of 200 spermatozoa were evaluated under a phase-contrast microscope at $1,000 \times$. For sperm head morphology, a total of 500 spermatozoa previously stained with William's dye were evaluated under a light microscope at 1,000× (Axner et al., 2002).

\section{Plasma membrane and acrosome integrity evaluation}

Plasma membrane integrity and acrosome integrity were evaluated by staining the spermatozoa with Ethidium homodimer-1 (EthD-1, Molecular probes Inc., Eugene, OR, USA) and fluorescein isothiocyanate conjugated peanut agglutinin (FITC-PNA, Sigma, St. Louis, MO, USA) (Kitiyanant et al., 2002). In brief, an aliquot of $5 \mu \mathrm{L}$ sperm suspension was mixed with an equal volume of $2 \mu \mathrm{M}$ EthD1 for $10 \mathrm{~min}$ at $37^{\circ} \mathrm{C}$. Subsequently, a $5 \mu \mathrm{L}$ of a $10 \mathrm{mg} / \mathrm{mL}$ salmon sperm DNA (Sigma-Aldrich Chemie GmbH, Steinheim, Germany) in phosphate buffered saline (PBS) was added to bind excessive EthD-1 for $3 \mathrm{~min}$ at $37^{\circ} \mathrm{C}$. After centrifugation, the spermatozoa were then smeared on a glass microscopic slide and fixed in $95 \%$ (v/v) ethanol for 30 s. Fixed spermatozoa were stained with $100 \mu \mathrm{g} / \mathrm{mL}$ FITC-PNA in PBS in a humidified chamber for $30 \mathrm{~min}$ at $4^{\circ} \mathrm{C}$ then rinsed with $4^{\circ} \mathrm{C}$ distilled water and allowed to air dry at $4^{\circ} \mathrm{C}$. The fluorescent labeled slides were kept in the dark until evaluation. A total of 200 spermatozoa per slide were randomly visualized using an epifluorescent microscope at $1,000 \times$ and then classified into 3 categories as previously described (Cheng et al., 1996).

\section{DNA integrity evaluation}

Sperm DNA integrity was evaluated by acridine orange dye as described by (Thuwanut and Chatdarong, 2009). In brief, sperm suspension was first smeared on the glass slide, allowed air dry and then fixed in freshly prepared Carnoy's solution (3:1 [v/v] methanol:glacial acetic acid) for overnight at room temperature. The slide containing spermatozoa were then stained with $1 \%(\mathrm{w} / \mathrm{v})$ acridine orange in distilled water for $5 \mathrm{~min}$. A total of 200 spermatozoa per slide were evaluated and classified as normal DNA integrity (green fluorescence) and denatured DNA (orange, yellow or red fluorescence).

\section{Statistical analysis}

Data was handled and statistically analyzed using the SAS statistical package (version 9, SAS Institute, Inc., 2002, Cary, NC, USA). Normal distribution of residuals from the statistical models was tested using UNIVARIATE procedure option NORMAL PLOT. Two-way analysis of variance was performed using PROC GLM procedure to compare the difference among mean numbers of percentage of spermatozoa motility, intact plasma membrane spermatozoa, intact acrosome spermatozoa and normal DNA integrity spermatozoa. Concentrations of L-carnitine, times and interaction between concentrations of L-carnitine and times were regarded as a fixed effect. Least-squares means were obtained from each class of the factors; and were compared by using least significant different test with Tukey-Kramer adjustment for multiple comparisons. All data was expressed as mean \pm SD. A $p$ value of less than 0.05 was considered statistically significant.

\section{RESULTS}

The characteristics of spermatozoa recovered from cauda epididymis (fresh spermatozoa) are shown in Table 1. Post-thawed spermatozoa characteristics including motility, plasma membrane integrity, DNA integrity and acrosome integrity are shown in Table 2, 3, 4, and 5, respectively. The percentages of motility, plasma membrane integrity, DNA integrity and acrosome integrity fresh spermatozoa were $80.75 \pm 4.87,78.40 \pm 5.24,94.98 \pm 2.81$, and 73.57 \pm 5.22 , respectively. These values were significantly greater than those obtained after freezing and thawing $(\mathrm{p}<0.05)$, indicating that cryopreservation process caused lethal damage to the spermatozoa. However, significantly higher motility was observed in $25 \mathrm{mM}$ L-carnitine group when compared with $0 \mathrm{mM}$ L-carnitine (control) group at $0 \mathrm{~h}$ and $2 \mathrm{~h}$ after thawing $(\mathrm{p}<0.05)$. Moreover, sperm motility at $2 \mathrm{~h}$ after thawing of $12.5 \mathrm{mM}$ and $25 \mathrm{mM}$ L-carnitine groups were significantly higher than $0 \mathrm{mM}$ L-carnitine group $(\mathrm{p}<0.05)$. Plasma membrane integrity, DNA integrity and acrosome integrity were not significantly different in all treatment groups and all examination times $(\mathrm{p}>0.05)$.

\section{DISCUSSION}

It has been accepted that oral administration of Lcarnitine is an effective option to improve semen quality in humans and some domestic animals (Kozink et al., 2004; Balercia et al., 2005). This sperm technology is important especially when cryopreservation is performed. Indeed,

Table 1. Characteristics of fresh cauda epididymal spermatozoa $($ mean \pm SD)

\begin{tabular}{lc}
\hline Sperm parameters & Fresh spermatozoa \\
\hline Motility (\%) & $81.67 \pm 3.83$ \\
Intact plasma membrane (\%) & $78.61 \pm 5.03$ \\
Normal DNA integrity (\%) & $95.17 \pm 2.74$ \\
Intact acrosome in live spermatozoa (\%) & $73.92 \pm 4.12$ \\
\hline
\end{tabular}

$\mathrm{SD}$, standard deviation. 
Table 2. Sperm motility (\%) of post-thawed cauda epididymal spermatozoa after thawing for $0 \mathrm{~h}(\mathrm{~T} 0), 2 \mathrm{~h}$ (T2) and $4 \mathrm{~h}$ (T4) in each experimental group (mean \pm SD)

\begin{tabular}{lllc}
\hline Group/time & \multicolumn{1}{c}{$\mathrm{T}_{0}$} & $\mathrm{~T}_{2}$ & $\mathrm{~T}_{4}$ \\
\hline $0 \mathrm{mM}$ L-carnitine & $51.25 \pm 10.25^{\mathrm{A}, \mathrm{a}}$ & $43.13 \pm 13.02^{\mathrm{A}, \mathrm{B}, \mathrm{a}}$ & $37.19 \pm 14.49^{\mathrm{B}, \mathrm{a}}$ \\
$12.5 \mathrm{mM}$ L-carnitine & $62.81 \pm 8.75^{\mathrm{A}, \mathrm{a}, \mathrm{b}}$ & $57.19 \pm 9.30^{\mathrm{A}, \mathrm{B}, \mathrm{b}}$ & $48.13 \pm 14.82^{\mathrm{B}, \mathrm{a}}$ \\
$25 \mathrm{mM}$ L-carnitine & $64.69 \pm 7.41^{\mathrm{A}, \mathrm{b}}$ & $58.44 \pm 9.78^{\mathrm{A}, \mathrm{B}, \mathrm{b}}$ & $48.75 \pm 15.00^{\mathrm{B}, \mathrm{a}}$ \\
$50 \mathrm{mM}$ L-carnitine & $55.94 \pm 9.87^{\mathrm{A}, \mathrm{a}, \mathrm{b}}$ & $47.81 \pm 13.16^{\mathrm{A}, \mathrm{B}, \mathrm{a}, \mathrm{b}}$ & $40.94 \pm 14.97^{\mathrm{B}, \mathrm{a}}$ \\
\hline
\end{tabular}

$\mathrm{SD}$, standard deviation.

Values within the same column followed by the different small letter superscripts, and within the same row followed by the different capital letter superscripts are significantly different $(\mathrm{p} \leq 0.05)$.

Table 3. Plasma membrane integrity (\%) of post-thawed cauda epididymal spermatozoa after thawing for $0 \mathrm{~h}$ (T0), $2 \mathrm{~h}$ (T2), and $4 \mathrm{~h}$ (T4) in each experimental group (mean $\pm \mathrm{SD})$

\begin{tabular}{lllc}
\hline Group/time & $\mathrm{T}_{0}$ & $\mathrm{~T}_{2}$ & $\mathrm{~T}_{4}$ \\
\hline $0 \mathrm{mM}$ L-carnitine & $67.19 \pm 9.98^{\mathrm{A}, \mathrm{a}}$ & $64.19 \pm 8.76^{\mathrm{A}, \mathrm{a}}$ & $61.91 \pm 7.99^{\mathrm{A}, \mathrm{a}}$ \\
$12.5 \mathrm{mM}$ L-carnitine & $69.56 \pm 6.70^{\mathrm{A}, \mathrm{a}}$ & $67.69 \pm 10.73^{\mathrm{A}, \mathrm{a}}$ & $65.09 \pm 6.22^{\mathrm{A}, \mathrm{a}}$ \\
$25 \mathrm{mM}$ L-carnitine & $66.69 \pm 8.26^{\mathrm{A}, \mathrm{a}}$ & $65.66 \pm 9.91^{\mathrm{A}, \mathrm{a}}$ & $62.78 \pm 9.20^{\mathrm{A}, \mathrm{a}}$ \\
$50 \mathrm{mM}$ L-carnitine & $68.56 \pm 8.44^{\mathrm{A}, \mathrm{a}}$ & $65.31 \pm 10.11^{\mathrm{A}, \mathrm{a}}$ & $61.69 \pm 11.10^{\mathrm{A}, \mathrm{a}}$ \\
\hline
\end{tabular}

SD, standard deviation.

Values within the same column followed by the different small letter superscripts, and within the same row followed by the different capital letter superscripts are significantly different $(\mathrm{p} \leq 0.05)$.

freezing and thawing frequently induce excessive generation of free radicals and ROS. Several kinds of antioxidant supplementation in semen extender have successfully used to improve epididymal spermatozoa quality during cryopreservation (Neuman et al., 2002; Pena et al., 2003). We therefore hypothesized that L-carnitine supplementation in a freezing extender would improve cat epididymal spermatozoa quality during cryopreservation. This is the first study to investigate the effect of L-carnitine supplementation in the freezing extender for cat epididymal spermatozoa.

Our results demonstrated that cryopreservation markedly reduced the spermatozoa quality, although the post-thawed spermatozoa quality was in an acceptable range (Tables 2 to 4). This result was also similar to previous reports (Axner et al., 2004; Thuwanut et al., 2010). In addition, sperm quality after cryopreservation, in terms of spermatozoa motility, intact plasma membrane and intact

Table 4. Sperm DNA integrity (\%) of post-thawed cauda epididymal spermatozoa after thawing for $0 \mathrm{~h}(\mathrm{~T} 0), 2 \mathrm{~h}$ (T2) and $4 \mathrm{~h}$ (T4) in each experimental group (mean $\pm \mathrm{SD}$ )

\begin{tabular}{lllc}
\hline Group/time & $\mathrm{T}_{0}$ & $\mathrm{~T}_{2}$ & $\mathrm{~T}_{4}$ \\
\hline $0 \mathrm{mM}$ L-carnitine & $91.38 \pm 9.26^{\mathrm{A}, \mathrm{a}}$ & $89.88 \pm 14.89^{\mathrm{A}, \mathrm{a}}$ & $84.56 \pm 19.65^{\mathrm{A}, \mathrm{a}}$ \\
$12.5 \mathrm{mM}$ L-carnitine & $89.34 \pm 14.82^{\mathrm{A}, \mathrm{a}}$ & $92.56 \pm 9.81^{\mathrm{A}, \mathrm{a}}$ & $91.56 \pm 11.80^{\mathrm{A}, \mathrm{a}}$ \\
$25 \mathrm{mM}$ L-carnitine & $83.09 \pm 23.11^{\mathrm{A}, \mathrm{a}}$ & $89.63 \pm 14.58^{\mathrm{A}, \mathrm{a}}$ & $89.53 \pm 12.50^{\mathrm{A}, \mathrm{a}}$ \\
$50 \mathrm{mM}$ L-carnitine & $86.88 \pm 18.97^{\mathrm{A}, \mathrm{a}}$ & $92.34 \pm 10.93^{\mathrm{A}, \mathrm{a}}$ & $92.34 \pm 8.69^{\mathrm{Aa}}$ \\
\hline
\end{tabular}

SD, standard deviation.

Values within the same column followed by the different small letter superscripts, and within the same row followed by the different capital letter superscripts are significantly different $(\mathrm{p} \leq 0.05)$.

Table 5. Sperm acrosome integrity (\%) of post-thawed cauda epididymal spermatozoa after thawing for $0 \mathrm{~h}$ (T0), 2 h (T2) and $4 \mathrm{~h}$ (T4) in each treatment and control (mean \pm SD)

\begin{tabular}{lccc}
\hline Group/time & $\mathrm{T}_{0}$ & $\mathrm{~T}_{2}$ & $\mathrm{~T}_{4}$ \\
\hline $0 \mathrm{mM}$ L-carnitine & $33.00 \pm 12.92^{\mathrm{A}, \mathrm{a}}$ & $33.59 \pm 13.24^{\mathrm{A}, \mathrm{a}}$ & $26.13 \pm 12.33^{\mathrm{A}, \mathrm{a}}$ \\
$12.5 \mathrm{mM}$ L-carnitine & $34.84 \pm 13.99^{\mathrm{A}, \mathrm{a}}$ & $31.66 \pm 15.03^{\mathrm{A}, \mathrm{a}}$ & $26.09 \pm 13.06^{\mathrm{A}, \mathrm{a}}$ \\
$25 \mathrm{mM}$ L-carnitine & $38.00 \pm 21.97^{\mathrm{A}, \mathrm{a}}$ & $35.38 \pm 18.56^{\mathrm{A}, \mathrm{a}}$ & $29.56 \pm 13.33^{\mathrm{A}, \mathrm{a}}$ \\
$50 \mathrm{mM}$ L-carnitine & $33.81 \pm 15.03^{\mathrm{A}, \mathrm{a}}$ & $29.16 \pm 14.79^{\mathrm{A}, \mathrm{a}}$ & $30.81 \pm 13.74^{\mathrm{A}, \mathrm{a}}$ \\
\hline
\end{tabular}

SD, standard deviation.

Values within the same column followed by the different small letter superscripts, and within the same row followed by the different capital letter superscripts are significantly different $(\mathrm{p} \leq 0.05)$. 
acrosome was decreased over the times of examination. It is worth noting that the post-thawed quality of epididymal sperm was generally lower than ejaculated spermatozoa possibly by the facts that they are different in structural membrane characteristics and the susceptibility to cold shock (White, 1993). The plasma membrane of mammalian spermatozoa is predominantly composed of polyunsaturated fatty acids (Alvarez and Storey, 1995), which can be reacted with free radical to damage the sperm cells. Therefore, the antioxidants are believed to prevent spermatozoa damage from aforementioned free radicals that may excessively generate during the freeze-thaw process. Although we did not find any protective effect of L-carnitine on plasma membrane integrity, the $25 \mathrm{mM}$ L-carnitine group provided the significantly higher motility than control when examined at $0 \mathrm{~h}$ and $2 \mathrm{~h}$ post thawing. These results suggest that the damages induced by an oxidative stress may cause only subtle changes of the plasma membrane structure.

The improvement of sperm motility has also been reported in other species. For examples, L-carnitine could improve stallion semen quality in asthenozoospermic semen (Cavallini et al., 2004). The effect of L-carnitine on improving human sperm motility has also been reported in oligo-, astheno- and terato-zoospermia (Costa et al., 1994; Balercia et al., 2005). These findings reinforce the hypothesis that L-carnitine may promote the cellular energetics (Lenzi et al., 2003) by transports long-chain acyl groups of fatty acids into sperm mitochondria, thereby improving flagella movement (Jeulin and Lewin, 1996).

After thawing, the intact acrosome spermatozoa were decreased in all treatment groups. This result showed that L-carnitine supplementation in freezing extender could not protect cat cryopreserved epididymal spermatozoa against acrosomal damage. This result is similar to the results of Yeste et al. (2010) reporting that dietary L-carnitine supplementation could not improve the acrosome integrity in ejaculated boar spermatozoa. Also, L-carnitine had no effect on DNA integrity of frozen-thawed spermatozoa. It is possible that the free radical scavengers within the semen extender were sufficient to protect the spermatozoa from oxidative stress generated during cryopreservation. In fact, the normal sperm DNA is less susceptible to this process (Zini et al., 2009), and in vitro antioxidant supplementations to normal DNA integrity spermatozoa have a limited consequence in DNA protection from ROS (Hughes et al., 1998; Donnelly et al., 1999; 2000; Chi et al., 2008).

In conclusion, the $25 \mathrm{mM}$ L-carnitine supplementation in cryopreserved sperm extender improves motility of cat epididymal spermatozoa during freezing thawing. The interactions between ROS and antioxidants supplemented into freezing extender in terms of subtle changes of plasma membrane and fertility should be further investigated.

\section{ACKNOWLEDGMENTS}

We would like to sincerely thank The Veterinary Public Health Division of The Bangkok Metropolitan Administration, Bangkok, Thailand for providing canine testicular samples. This study was financially supported by grant of Faculty of Veterinary Science, Mahidol University.

\section{REFERENCES}

Abd-Allah, A. R., G. K. Helal, A. A. Al-Yahya, A. M. Aleisa, S. S. Al-Rejaie, and S. A. Al-Bakheet. 2009. Pro-inflammatory and oxidative stress pathways which compromise sperm motility and survival may be altered by L-carnitine. Oxid. Med. Cell. Longev. 2:73-81.

Agarwal, A., K. P. Nallella, S. S. Allamaneni, and T. M. Said. 2004. Role of antioxidants in treatment of male infertility: An overview of the literature. Reprod. Biomed. Online 8:616-627.

Aitken, R. J. and A. J. Koppers. 2011. Apoptosis and DNA damage in human spermatozoa. Asian J. Androl. 13:36-42.

Alvarez, J. G. and B. T. Storey. 1995. Differential incorporation of fatty acids into and peroxidative loss of fatty acids from phospholipids of human spermatozoa. Mol. Reprod. Dev. 42:334-346.

Andersen, K. 1975. Insemination with frozen dog semen based on a new insemination technique. Reprod. Domest. Anim. 10:1-4.

Axner, E., U. Hermansson, and C. Linde-Forsberg. 2004. The effect of Equex STM paste and sperm morphology on postthaw survival of cat epididymal spermatozoa. Anim. Reprod. Sci. 84:179-191.

Axner, E., B. S. Pukazhenthi, D. E. Wildt, C. Linde-Forsberg, and R .E. Spindler. 2002. Creatine phosphokinase in domestic cat epididymal spermatozoa. Mol. Reprod. Dev. 62:265-270.

Bailey, J. L., J. F. Bilodeau, and N. Cormier. 2000. Semen cryopreservation in domestic animals: A damaging and capacitating phenomenon minireview. J. Androl. 21:1-7.

Balercia, G., F. Regoli, T. Armeni, A. Koverech, F. Mantero, and M. Boscaro. 2005. Placebo-controlled double-blind randomized trial on the use of L-carnitine, L-acetylcarnitine, or combined L-carnitine and L-acetylcarnitine in men with idiopathic asthenozoospermia. Fertil. Steril. 84:662-671.

Cavallini, G., A. P. Ferraretti, L. Gianaroli, G. Biagiotti, and G. Vitali. 2004. Cinnoxicam and L-carnitine/acetyl-L-carnitine treatment for idiopathic and varicocele-associated oligoasthenospermia. J. Androl. 25:761-770; discussion 771762.

Cerolini, S., A. Maldjian, F. Pizzi, and T. M. Gliozzi. 2001. Changes in sperm quality and lipid composition during cryopreservation of boar semen. Reproduction 121:395-401.

Cheng, F. P., A. Fazeli, W. F. Voorhout, A. Marks, M. M. Bevers, and B. Colenbrander. 1996. Use of peanut agglutinin to assess the acrosomal status and the zona pellucida-induced acrosome reaction in stallion spermatozoa. J. Androl. 17:674-682.

Chi, H. J., J. H. Kim, C. S. Ryu, J. Y. Lee, J. S. Park, D. Y. Chung, S. Y. Choi, M. H. Kim, E. K. Chun, and S. I. Roh. 2008. Protective effect of antioxidant supplementation in spermpreparation medium against oxidative stress in human spermatozoa. Hum. Reprod. 23:1023-1028. 
Costa, M., D. Canale, M. Filicori, S. D'Lddio, and A. Lenzi. 1994. L-carnitine in idiopathic asthenozoospermia: A multicenter study. Andrologia 26:155-159.

Donnelly, E. T., N. McClure, and S. E. M. Lewis. 1999. The effect of ascorbate and alpha-tocopherol supplementation in vitro on DNA integrity and hydrogen peroxide-induced DNA damage in human spermatozoa. Mutagenesis 14:505-512.

Donnelly, E. T., N. McClure, and S. E. Lewis. 2000. Glutathione and hypotaurine in vitro: Effects on human sperm motility, DNA integrity and production of reactive oxygen species. Mutagenesis 15:61-68.

Hammerstedt, R. H., J. K. Graham, and J. P. Nolan. 1990. Cryopreservation of mammalian sperm: What we ask them to survive. J. Androl. 11:73-88.

Hughes, C. M., S. E. Lewis, V. J. McKelvey-Martin, and W. Thompson. 1998. The effects of antioxidant supplementation during Percoll preparation on human sperm DNA integrity. Hum. Reprod. 13:1240-1247.

Jeulin, C., J. L. Dacheux, and J. C. Soufir. 1994. Uptake and release of free L-carnitine by boar epididymal spermatozoa in vitro and subsequent acetylation rate. J. Reprod. Fertil. 100:263-271.

Jeulin, C. and L. M. Lewin. 1996. Role of free L-carnitine and acetyl-L-carnitine in post-gonadal maturation of mammalian spermatozoa. Hum. Reprod. Update 2:87-102.

Kim, S. H., D. H. Yu, and Y. J. Kim. 2010a. Apoptosis-like change, ROS, and DNA status in cryopreserved canine sperm recovered by glass wool filtration and Percoll gradient centrifugation techniques. Anim. Reprod. Sci. 119:106-114.

Kim, S. H., D. H. Yu, and Y. J. Kim. 2010b. Effects of cryopreservation on phosphatidylserine translocation, intracellular hydrogen peroxide, and DNA integrity in canine sperm. Theriogenology 73:282-292.

Kitiyanant, Y., B. Chaisalee, and K. Pavasuthipaisit. 2002. Evaluation of the acrosome reaction and viability in buffalo spermatozoa using two staining methods: The effects of heparin and calcium ionophore A23187. Int. J. Androl. 25:215222.

Kobayashi, D., I. Tamai, Y. Sai, K. Yoshida, T. Wakayama, Y. Kido, J. Nezu, S. Iseki, and A. Tsuji. 2007. Transport of carnitine and acetylcarnitine by carnitine/organic cation transporter (OCTN) 2 and OCTN3 into epididymal spermatozoa. Reproduction 134:651-658.

Kozink, D. M., M. J. Estienne, A. F. Harper, and J. W. Knight. 2004. Effects of dietary L-carnitine supplementation on semen characteristics in boars. Theriogenology 61:1247-1258.

Lenzi, A., F. Lombardo, P. Sgro, P. Salacone, L. Caponecchia, F. Dondero, and L. Gandini. 2003. Use of carnitine therapy in selected cases of male factor infertility: A double-blind crossover trial. Fertil. Steril. 79:292-300.
Neuman, S. L., T. L. Lin, and P. Y. Heste. 2002. The effect of dietary carnitine on semen traits of white Leghorn roosters. Poult. Sci. 81:495-503.

Pena, F. J., A. Johannisson, M. Wallgren, and H. Rodriguez Martinez. 2003. Antioxidant supplementation in vitro improves boar sperm motility and mitochondrial membrane potential after cryopreservation of different fractions of the ejaculate. Anim. Reprod. Sci. 78:85-98.

Pena, F. J., F. Saravia, A. Johannisson, M. Walgren, and H. Rodriguez-Martinez. 2005. A new and simple method to evaluate early membrane changes in frozen-thawed boar spermatozoa. Int. J. Androl. 28:107-114.

Platz, C. C., Jr., and S. W. Seager. 1978. Semen collection by electroejaculation in the domestic cat. J. Am. Vet. Med. Assoc. 173:1353-1355.

Stradaioli, G., L. Sylla, R. Zelli, P. Chiodi, and M. Monaci. 2004. Effect of L-carnitine administration on the seminal characteristics of oligoasthenospermic stallions. Theriogenology 62:761-777.

Thomson, L. K., S. D. Fleming, R. J. Aitken, G. N. De Iuliis, J. A. Zieschang, and A. M. Clark. 2009. Cryopreservation-induced human sperm DNA damage is predominantly mediated by oxidative stress rather than apoptosis. Hum. Reprod. 24:20612070.

Thuwanut, P. and K. Chatdarong. 2009. Incubation of post-thaw epididymal cat spermatozoa with seminal plasma. Reprod. Domest. Anim. 44 (Suppl 2):381-384.

Thuwanut, P., K. Chatdarong, A. Johannisson, A. S. Bergqvist, L. Soderquist, and E. Axner. 2010. Cryopreservation of epididymal cat spermatozoa: effects of in vitro antioxidative enzymes supplementation and lipid peroxidation induction. Theriogenology 73:1076-1087.

Tittarelli, C., C. A. Savignone, E. Arnaudin, M. C. Stornelli, M. A. Stornelli, and R. L. de la Sota. 2006. Effect of storage media and storage time on survival of spermatozoa recovered from canine and feline epididymides. Theriogenology 66:1637-1640.

White, I. G. 1993. Lipids and calcium uptake of sperm in relation to cold shock and preservation: A review. Reprod. Fertil. Dev. 5:639-658.

Yeste, M., S. Sancho, M. Briz, E. Pinart, E. Bussalleu, and S. Bonet. 2010. A diet supplemented with L-carnitine improves the sperm quality of Pietrain but not of Duroc and Large White boars when photoperiod and temperature increase. Theriogenology 73:577-586.

Zini, A., M. San Gabriel, and A. Baazeem. 2009. Antioxidants and sperm DNA damage: a clinical perspective. J. Assist. Reprod. Genet. 26:427-432. 